\title{
Did the COVID-19 Pandemic Make Consumers Shop Alone? The Role of Emotions and Interdependent Self-Construal
}

\author{
Wojciech Trzebiński *(D), Radosław Baran (D) and Beata Marciniak (D) \\ SGH Warsaw School of Economics, Collegium of Management and Finance, 02-554 Warszawa, Poland; \\ rbaran@sgh.waw.pl (R.B.); bmarci@sgh.waw.pl (B.M.) \\ * Correspondence: wtrzebi@sgh.waw.pl
}

Citation: Trzebiński, W.; Baran, R.; Marciniak, B. Did the COVID-19 Pandemic Make Consumers Shop Alone? The Role of Emotions and Interdependent Self-Construal. Sustainability 2021, 13, 6361. https:// doi.org/10.3390/su13116361

Academic Editor: Andrea Pérez

Received: 11 May 2021

Accepted: 31 May 2021

Published: 3 June 2021

Publisher's Note: MDPI stays neutral with regard to jurisdictional claims in published maps and institutional affiliations.

Copyright: (c) 2021 by the authors. Licensee MDPI, Basel, Switzerland. This article is an open access article distributed under the terms and conditions of the Creative Commons Attribution (CC BY) license (https:/ / creativecommons.org/licenses/by/ $4.0 /)$.

\begin{abstract}
The paper aims to assess the impact of the COVID-19 pandemic and possible future global epidemic events on shopping behavioral patterns. Specifically, the paper investigates consumer pandemic-related isolation behavior (which manifests itself via preference for shopping without leaving home, and avoiding contact with other people while shopping offline) as a consequence of consumer interdependent self-construal, with the mediating role of consumer pandemic-related emotions of disgust, fear for oneself, fear for others, and sadness. The results of two surveys conducted in different stages of the COVID-19 pandemic in Poland (October 2020, and January 2021, respectively) suggest two opposing indirect effects of interdependent self-construal on isolation behavior: a positive effect through disgust, and a negative effect through sadness. Additionally, a positive indirect effect through fear was visible in the second study. Moreover, two dimensions of interdependent self-construal (i.e., vertical and horizontal) are demonstrated to have opposing effects (a positive effect and a negative one, respectively) on pandemic-related disgust, and in turn on isolation behavior. The above results indicate that, in the context of the pandemic, consumer self-construal influences pandemic-related emotions, and in turn consumers' tendency to isolate themselves. Implications for marketers and society were discussed from the perspective of economic and sustainability goals.
\end{abstract}

Keywords: COVID-19 pandemic; consumer isolation behavior; emotions; self-construal; horizontal collectivism; vertical collectivism

\section{Introduction}

The COVID-19 pandemic is considered to be a long-term phenomenon, and to mark the "pandemic era" characterized by the presence of various epidemics or pandemics calling for global response [1,2], and influencing patterns of consumer behavior in the perspective of sustainability (e.g., [3-6]). In this paper, we aim to assess the impact of the COVID-19 pandemic and the possible future global epidemic events on shopping behavioral patterns. Specifically, in the context of a pandemic of a contagious disease, it may be expected that the relationship with other people, who potentially may be sources of infection, and suffer the same pandemic situation, may play a crucial role in that changed consumer behavior. Consumer isolation from other people may influence economic welfare, psychological well-being, and health, thus being important for sustainability issues. Therefore, our research considers consumer isolation behavior as a dependent variable, and the personal trait of interdependent self-construal (a degree to which one depicts the self as part of the social context) as an independent variable. As people may be deeply involved in a pandemic situation, we consider emotions as mediators.

The existing literature provides evidence for two opposite patterns of consumer behavior emerging as a response to the pandemic. On the one hand, consumers show a tendency to isolate themselves while buying and using products [7-15]. On the other hand, consumers may tend to stick together with other people, feeling community with 
them [15-17]. Therefore, we pose the question: what determines which of the above two reactions is dominant? This question may be relevant both for marketers and policymakers, who may aim to regulate consumer tendency to isolate themselves.

Considering interdependent self-construal, we propose that in the pandemic situation, it may trigger various emotions (like disgust with other people, fear for oneself or others, and sadness with the pandemic-related restrictions in contacting other people). Those emotions may have, in turn, different influences on the isolation behavior (i.e., disgust and fear may increase a tendency to isolate oneself, while sadness may decrease it).

To our best knowledge, there is currently no research linking interdependent selfconstrual, pandemic-related emotions, and consumer pandemic-related isolation behavior. Therefore, this paper aims to bridge this gap. Below, we develop hypotheses on the mechanisms linking interdependent self-construal, pandemic-related emotions, and consumer isolation behavior. Next, we test them in two studies conducted among Polish young adults in two stages of the COVID-19 pandemic in 2020-2021. Finally, we discuss the results from the perspectives of consumer behavior theory and their implications for marketers and society.

\section{Theoretical Background}

In the consumer behavior theory, the concept of consumer isolation behavior appears to be surprisingly understudied. Quite the contrary, people have been viewed rather as seeking contact with other people or avoiding social isolation, e.g., through social media [18], and brand communities [19]. However, the topic of consumer isolation emerges in the context of infectious disease epidemics. For example, Chuo [20] analyzed 10-year longitudinal survey data obtained from restaurant diner club members during the SARS epidemic in 2003, and the avian influenza epidemic in 2013. The research employed a fivestage model of self-protective behavior in response to an epidemic, starting with learning of the outbreak and going through acknowledging the risk and leading to engagement in self-protective behavior in the form of avoiding dining out in restaurants and preferring disinfection certified restaurants. The study found that over time, consumers adopted more protective behavior. In line with that, Jung et al. [21] demonstrated that during the MERS epidemics in 2015, consumers reduced their expenditures on food outside the home, as well as at department stores, while increased their e-commerce expenditures. Cahyanto et al. [22] applied the Health Belief Model to study travel avoidance due to the Ebola epidemic in 2014, finding the perceived risk of contracting the illness to be a significant factor. Clearly, in the above studies, the behavioral consequences of epidemics are related to isolating oneself from other people, may it be by eating at home, shopping from home, or hesitating to travel.

Like in the case of earlier epidemics, the existing literature on the COVID-19 pandemic impact on people's behavior investigates various forms of isolating oneself from other people as potential sources of infection. Escandon-Barbosa et al. [23] used the theory of reasoned action to study voluntary self-isolation, as a form of coping with an epidemic, in Spain and Columbia. Interestingly, subjective norms were significantly related to selfisolation intention among Spaniards, but not Colombians. This may suggest that isolation behavior may not necessarily be motivated by pro-social attitudes. Laato et al. [24] found that the general tendency for self-isolation behavior is positively related to the perceived severity of COVID-19. Turning to consumer behavior, Szymkowiak et al. [25] investigated the various consequences of infection threat on shopping behavior, including isolation in the form of contact limitation (no accompanying people, avoiding high in-store traffic, limiting shopping visits), and keeping distance from other people when waiting in line or choosing products. Those authors evidenced that higher arousal and lower pleasure stemming from the infection threat may increase this isolation behavior. Other specific forms of isolation behavior related to the COVID-19 pandemic include staying at home [9], online shopping $[12,13,15]$, avoiding eating in restaurants $[15,26]$, avoiding visits to movie theaters and groceries [26], avoiding travel [14] and public transportation [8,27], using 
VR instead of traveling [15], "untact tourism" (i.e., minimized contact with other people during travels) [7], working out outdoors vs. in fitness clubs, using robot assistants vs. human assistants [10], or even negative attitudes to other ethnic groups [11]. On the other hand, consumers may react to the pandemic by feeling community with other people in the pandemic situation [16]. Those responses may manifest themselves in changes in the hierarchy of values, such that common good prevails over individual freedom [15], feeling a connection with other people, willingness to help other people and gratitude to other people [17]. We embrace all the above manifestations under one dimension we call consumer isolation behavior. We define this as consumer tendency to shop alone (vs. together with other people), i.e., preferably online, and if offline, then with minimal or no assistance of or contact with other people, including staff and other shoppers. As such, consumer isolation behavior comprises, but is not limited to, in-shop contact limitation and distancing studied by Szymkowiak et al. [25]. Although related, the concept of consumer isolation behavior is distinct from several other concepts discussed in the existing literature on pandemic-related behavior. Firstly, consumer isolation behavior is not the same as voluntary self-isolation [23] as consumers may shop alone (vs. together) not specifically because they obey the restrictions or cope with the pandemic, but because they just do not want (vs. want) to get in touch with other people. Secondly, consumer isolation behavior does not equal sheltering-in-place [9], as the former covers also consumer outdoor behavior. Thirdly, consumer isolation behavior differs from loneliness [28], as the latter concept refers rather to an emotional state that, however potentially related to isolation behavior, may trigger the opposite, as a consumer may want to get in touch with other people, also physically.

In the light of the above ambiguity about the two opposite consumer reactions to the COVID-19 pandemic, i.e., isolating oneself from other people vs. feeling community with other people, one may pose a question: what shapes the direction of the pandemic impact on consumer isolation behavior? To our best knowledge, the current literature does not explain this. Therefore, we aim to bridge that gap in our research, proposing the differential role of certain pandemic-related emotions, and considering consumer interdependent self-construal as the antecedent of those emotions.

\section{Hypotheses Development}

\subsection{Pandemic-Related Emotions as Factors of Consumer Isolation Behavior}

As discussed above, the pandemic situation may influence consumer behavior through at least two opposite pathways: isolation vs. community. Some consumers may tend to shelter and avoid other people, while other consumers may react oppositely, tending to stay in contact with other people, even if this may be against the pandemic-related restrictions. We propose those two opposite mechanisms of consumer reaction to the pandemic are driven by different emotions evoked by the pandemic (we call them pandemic-related emotions). The existing literature considers the pandemic to trigger various emotions like disgust, fear, or sadness [29-33]. Some of them, like disgust or fear, may lead consumers to isolation, while others, like sadness, may lead consumers to contact other people.

We focus on four specific consumer pandemic-related emotions, i.e., disgust (i.e., feeling an urge to avoid other people while shopping offline), fear for oneself (i.e., being scared of the possibility of being endangered by other people while shopping offline), fear for others (i.e., being scared of the possibility of endangering other people while shopping offline), and sadness (i.e., feeling sad about pandemic-related limitations or restrictions in contacting other people).

Disgust is considered a primal emotion characterized by a tendency to distance oneself from a focal object [34]. People exposed to a scenario in which shop assistants did not obey social distancing restrictions related to the pandemic showed a higher level of disgust [35]. Disgust is evidenced to be connected with a tendency to distance oneself from other people [34] and avoid diseases [36]. Therefore, we expect that 
Hypothesis 1 (H1). Pandemic-related disgust is positively related to pandemic-related consumer isolation behavior.

Likewise, pandemic-related fear for oneself or others may result in isolation behavior. Szymkowiak et al. [25] found that arousal (vs. pleasure) in-store is positively related to actions undertaken by consumers to improve control over the possible COVID-19 infection. Employees with fear of the pandemic are demonstrated to employ avoidance coping behavior (e.g., leaving work as soon as possible, sleeping more than usual) which appears generally related to isolation [37]. In line with the above, the perceived risk of being infected with Ebola was positively related to travel avoidance [22]. The perception of COVID-19 infection risk and the risk of severe disease was related to reduced visits to restaurants, movie theaters, groceries, and the use of public transportation [26]. Eventually, perceived COVID-19 severity was related to the increased general self-isolation [24]. Therefore, we expect that

Hypothesis 2 (H2). The emotions of:

(a) pandemic-related fear for oneself

(b) pandemic-related fear for others

are positively related to pandemic-related consumer isolation behavior.

On the other hand, sadness may increase the need to contact other people [38], especially when the sadness is related to restrictions in those contacts. The emotion of sadness is related to the theme of loss and thus it may evoke a goal to change the existing circumstances as a means to repair mood and compensate for the loss [39]. As such, pandemic-related sadness may trigger a tendency to regain contact with other people, even if it is not in line with restrictions, or may be associated with a higher risk of infection. Therefore, we expect that

Hypothesis 3 (H3). Pandemic-related sadness is negatively related to pandemic-related consumer isolation behavior.

\subsection{Interdependent Self-Construal as a Factor of Pandemic-Related Emotions}

As pandemic-related emotions discussed above pertain to interactions with other people, and so does pandemic-related isolation behavior, consumer perception of the self concerning others (i.e., the individual trait of interdependent self-construal) may act as an important factor. Interdependent individuals pay more attention to their relationship with other people and social roles, as opposed to the attention to their own autonomy and uniqueness [40,41]. People differ in the degree to which the interdependent self-construal is dominant, and that long-term variation may be determined by the culture in such a way that interdependent self-construal is more dominant in collectivistic vs. individualistic cultures [41].

Below we offer a set of propositions on how interdependent self-construal may shape pandemic-related emotions and, in turn, consumer isolation behavior. Different emotions we will propose to be enhanced by the interdependent self (e.g., fear for others and sadness) may have opposite effects on isolation behavior. Therefore, we do not formulate predictions about the total effect of interdependent self-construal. Rather, we point out various affective mechanisms through which self-construal may operate. Although this provides no basis for behavioral outcome prediction, it suggests how one may regulate consumer isolation behaviors by identifying and influencing consumer self-construal and emotions.

Considering pandemic-related disgust, at least two opposite mechanisms, both induced by interdependent self-construal, may be theoretically derived. On the one hand, interdependent self-construal may trigger more attention to other people, as the relational context is more important, and the self is more closely connected to others [42]. As such, interdependent self-construal may make people more sensitive to the potential infection 
coming from other people, which may lead to disgust. Interdependent individuals are demonstrated to better recognize the facial expression of disgust [43]. Moreover, interdependent self-construal may enhance the psychological goals of the fulfillment of obligations and responsibilities, thus leading to more preventive regulatory focus, characterized by emotional responses, attitudes and behaviors that are concentrated on ensuring safety and being vigilant and sensitive to negative outcomes [41,44]. Consequently, the interdependent self may trigger more attention to the possibility of being infected by other people, which may evoke disgust as a primal safety-keeping reaction. Therefore, a more dominant interdependent self-construal may enhance the pandemic-related disgust, and in turn increase the consumer isolation behavior. We will further refer to this mechanism as the attention-related mechanism. On the other hand, perceiving oneself as more connected with other people [41] may lead one to consider other people in a community to be more similar to and identifiable with oneself. Identity, in turn, may reduce the disgust response, e.g., smokers are shown to be less disgusted by cigarettes vs. non-smokers [34]. In that case, the more dominant interdependent self-construal may diminish the pandemic-related disgust, and in turn decrease the consumer isolation behavior. We will further refer to this mechanism as the identity-related mechanism. This way, interdependent self-construal may diminish the degree of pandemic-related disgust. Consequently, we formulate two competing hypotheses:

Hypothesis 4 (H4). (Attention-related mechanism). (a) Consumer interdependent self-construal is positively related to pandemic-related disgust and (b) consumer interdependent self-construal has a positive indirect effect on pandemic-related consumer isolation behavior through pandemicrelated disgust.

Hypothesis 5 (H5). (Identity-related mechanism). (a) Consumer interdependent self-construal is negatively related to pandemic-related disgust and (b) consumer interdependent self-construal has a negative indirect effect on pandemic-related consumer isolation behavior through pandemicrelated disgust.

One may ask what may determine which mechanism (i.e., attention-based or identitybased) prevails. Referring to the cultural background of the interdependent self-construal, we consider the distinction between horizontal and vertical cultures. The first type emphasizes equality, while the second one emphasizes hierarchy in relationships with other people [41]. This distinction translates into the perception of the self [45]. As in horizontal collectivism, the self is perceived as more equal to other people [45,46], the identity-related mechanism may prevail. On the other hand, as in vertical collectivism, the self is perceived as unequal, or different than at least part of the community [45,46], the identity-related mechanism may be weaker, and therefore, the attention-related mechanism may prevail. Consequently, we expect that

Hypothesis 6 (H6). (Attention-related mechanism). (a) Consumer vertical collectivism is positively related to pandemic-related disgust and (b) consumer vertical collectivism has a positive indirect effect on pandemic-related consumer isolation behavior through pandemic-related disgust.

Hypothesis 7 (H7). (Identity-related mechanism). (a) Consumer horizontal collectivism is negatively related to pandemic-related disgust and (b) consumer horizontal collectivism has a negative indirect effect on pandemic-related consumer isolation behavior through pandemic-related disgust.

Interdependent self-construal may also increase the pandemic-related fear for oneself through higher attention to other people and preventive focus, i.e., consumers may be more scared of the possibility of being infected by other people, which in turn may lead to increased consumer isolation behavior. Therefore, we expect that 
Hypothesis 8 (H8). (a) Consumer interdependent self-construal is positively related to pandemicrelated fear for oneself and (b) consumer interdependent self-construal has a positive indirect effect on pandemic-related consumer isolation behavior through pandemic-related fear for oneself.

As the interdependent self is related to sociocentrism [41], individuals high in interdependent self-construal may be more sensitive to the possibility that other people may be infected. This higher sensitivity, together with the preventive focus resulting from interdependent self-construal, may cause higher pandemic-related fear for other people, and in turn increase the consumer isolation behavior. Formally,

Hypothesis 9 (H9). (a) Consumer interdependent self-construal is positively related to pandemicrelated fear for other people and (b) consumer interdependent self-construal has a positive indirect effect on pandemic-related consumer isolation behavior through pandemic-related fear for other people.

Another possible consequence of sociocentrism related to the interdependent self is that the pandemic-imposed restrictions in contacting other people may be more harmful. Thus, consumers high in interdependent self-construal may perceive the pandemic situation more like a loss related to an important part of their life, which may evoke pandemic-related sadness, and in turn decrease the consumer isolation behavior. Therefore, we expect that

Hypothesis 10 (H10). (a) Consumer interdependent self-construal is positively related to pandemicrelated sadness and (b) consumer interdependent self-construal has a negative indirect effect on pandemic-related consumer isolation behavior through pandemic-related sadness.

We test the above hypotheses in two studies conducted in different stages of the COVID-19 pandemic in Poland. Study 1 comprises interdependent self-construal as an independent variable, pandemic-related emotions as mediators, and isolation behavior as a dependent variable. We ran that study in October 2020, during the "2nd wave" of the epidemic, when the number of cases was rising. Study 2 includes also the horizontal vs. vertical distinction. We ran that study in January 2021, after the 2nd wave, when the number of cases was stabilized and the vaccination program was launched.

\section{Study 1 (October 2020)}

4.1. Method

\subsubsection{Procedure}

In October 2020, during the "2nd wave" of the epidemic, when the number of cases was rising [47], online consumer panel participants (533 adult Poles aged between 20 and 35 , either working or studying at a university, and having university education ongoing or completed, $58.7 \%$ females, $\mathrm{M}_{\mathrm{age}}=28.3, \mathrm{SD}=4.8$ ) were asked to imagine they attempted to buy electronic products. First, they rated the degree of their isolation behavior during the purchase. Then, they were asked whether they had thought of the pandemic while answering the previous questions, related to isolation behavior ( $87 \%$ confirmed they had). Next, the participants rated their pandemic-related emotions, referring to the imagined situation of buying electronic products in an offline store. Then, the degree of interdependent self-construal was measured, followed by demographics. To avoid the "self-generated validity" [48], in both studies, we measured the studied variables in the order running counter to our hypothesized causality [49], i.e., we started the measurements with the isolation behavior, through emotions, and we finished with self-construal.

\subsubsection{Measurements}

Consumer isolation behavior. Eleven items were developed for this study to measure consumer isolation behavior. A sliding response scale coded from 0 to 100 was used. The measurements were subjected to exploratory factor analysis (EFA; principal components, $\mathrm{KMO}=0.821$, Bartlett's $p=0.000$, VARIMAX rotation) showing three components with 
eigenvalues above 1 . Four items heavily loaded on the first component (factor loadings above $0.500 ; 24.3 \%$ of variance, $\alpha=0.798$, 'I would prefer having little contact with other people during the purchase.' , 'If the price in an offline store was the same as in an online store, I would prefer to buy online.', 'Preferably, I would complete the purchase staying home.', 'Definitely, I would prefer to shop alone.'), and those were averaged to measure consumer isolation behavior with a single index. Unlike Cahyanto et al. [22], the item statements did not refer to the pandemic context. This way, we attempted to reduce possible demand biases (e.g., the participants might overrate their isolation behavior to confirm the impact of the pandemic).

Pandemic-related emotions. Pandemic-related emotions were measured with items related to the offline shopping experience. They directly followed the question about thinking on the pandemic, which was intended to provide the pandemic context. A sliding response scale coded from 0 to 100 was used. For pandemic-related disgust, we used six items inspired by Shimp and Stuart's [50] scale for disgust $(\alpha=0.917)$, referring to physical contact with other people ('I would experience kind of reluctance to contact other people in a shop.', 'I would feel aversion to contacting other shoppers.', 'I would feel uncomfortable imagining other people close to me.', 'It would be uncomfortable for me to contact a salesperson.', 'I would distance myself from a salesperson.'). Pandemicrelated fear was measured with three items inspired by Duhachek [51]. The statements for pandemic-related fear for oneself $(\alpha=0.949)$ were 'I would be a bit scared that contact with other people in a shop could be dangerous for me.', 'I would be frightened I would be endangered while contacting other people.', 'I would feel anxious if I had to contact other people.'. The corresponding statements for pandemic-related fear for other people ( $\alpha=0.941)$ were 'I would be a bit scared that contact with me could be dangerous for other people in a shop.', 'I would be frightened other people would be endangered while contacting me.', 'I would fear for other people if I had to contact them.'. For pandemicrelated sadness, we used five items inspired by Williams and Aaker's [52] scale for sadness. The statements $(\alpha=0.945)$ refer to the limited possibility of contacting other people e.g., 'I would be sad if I could not contact other people.', 'I would be sorry if my contact with other people was limited.', 'I would feel lonely not contacting other people.', 'I would find it hard if there were difficulties in contacting a store', 'I would feel helpless in this situation.'. All items for pandemic-related emotions were subjected to EFA (principal components, $\mathrm{KMO}=0.915$, Bartlett's $p=0.000$ ), and four components with the highest eigenvalues (the first component accounted for $29.4 \%$ of the variance, which suggests no common method variance issue [53] were rotated with VARIMAX. The items loaded on those rotated components (loadings above 0.500 ) in line with the measurement scales for the four pandemic-related emotions, thus supporting discriminant validity [54]. To assess the discriminant validity of the measurements of the isolation behavior and disgust constructs (which are conceptually similar as both refer to avoiding other people, in terms of behavior and emotions, respectively), we ran EFA for those measurement scales (KMO $=0.907$, Bartlett's $p=0.000$ ). Two components with eigenvalues above one were obtained (the first component accounted for $45.7 \%$ of the variance). The items loaded on the two rotated components (loadings above 0.500 ) in line with the measurement scales. For each emotion, the corresponding items were averaged into a single index.

Interdependent self-construal. We used the Polish adaptation [55] of items from Singelis [56] to measure independent and interdependent self-construal (nine items for each construct). A slider response scale coded from 0 to 100 was used. Based on reliability analysis, we excluded one item from the interdependent self-construal scale ('Even when I strongly disagree with group members, I avoid an argument.'), as it showed poor correlation with the other items of the scale and lowered its Cronbach's alpha. To assess the discriminant validity for the two self-construal scales, all remaining items were subjected to EFA $(\mathrm{KMO}=0.847$, Bartlett's $p=0.000)$. The two components with the highest eigenvalues (the first component accounted for $22.9 \%$ of the variance) were rotated with VARIMAX, and items loaded on those components (loadings above 0.500 ) in line with the two constructs, 
apart from one item from the interdependent self-construal scale, and two items from the independent self-construal scale. Consequently, we averaged seven items from the interdependent self-construal scale $(\alpha=0.838)$ into a single index for further analysis.

\subsection{Results}

In a parallel mediation model (PROCESS, Hayes model 4) with pandemic-related emotions as mediators, consumer interdependent self-construal as an independent variable, and consumer isolation behavior as a dependent variable (Figure $1 ; \beta_{\text {total }}=0.123, \mathrm{t}=2.862$, $p=0.004 ; \beta_{\text {direct }}=0.122, t=3.189, p=0.002, \mathrm{VIFs}<2.7$ ) (throughout the paper, all coefficients are standardized, and all confidence intervals for indirect effects are based on 5000 bootstrap samples), a positive effect of pandemic-related disgust on isolation behavior occurred $(\beta=0.429, \mathrm{t}=8.656, p<0.0001)$, supporting H1. Interdependent self-construal has a positive effect on disgust $(\beta=0.199, t=4.677, p<0.0001)$, as well as an indirect effect on isolation behavior through disgust $(\beta=0.085, \mathrm{CI} 95 \%(0.040,0.135))$, thus supporting $\mathrm{H} 4$ (based on the attention-related mechanism) over the competing H5 (based on the identityrelated mechanism). No effect of pandemic-related fear for oneself on isolation behavior was observed $(p>0.5)$, thus providing no support for H2a. The effect of interdependent self-construal on fear for oneself was positive $(\beta=0.309, t=7.473, p<0.0001)$, which supports $\mathrm{H} 8 \mathrm{a}$, while $\mathrm{H} 8 \mathrm{~b}$ is not supported as the indirect effect of interdependent selfconstrual on isolation behavior through fear for oneself is nonsignificant. The effect of pandemic-related fear for others on isolation behavior was nonsignificant $(p>0.05)$, thus providing no support for $\mathrm{H} 2 \mathrm{~b}$. The effect of interdependent self-construal on fear for others was positive ( $\beta=0.354, t=8.717, p<0.0001$ ), which supports $\mathrm{H} 9 \mathrm{a}$, while $\mathrm{H} 9 \mathrm{~b}$ is not supported as the indirect effect of interdependent self-construal on isolation behavior through fear for others is nonsignificant. Finally, a negative effect of pandemic-related sadness on isolation behavior occurred $(\beta=-0.368, t=9.586, p=0.000)$, thus supporting H3. The effect of interdependent self-construal on sadness was positive $(\beta=0.293, t=7.056$, $p<0.0001)$, and the indirect effect on isolation behavior through sadness was negative $(\beta=-0.108, \mathrm{C} 195 \%(-0.154,-0.066))$, thus providing support for $\mathrm{H} 10$.

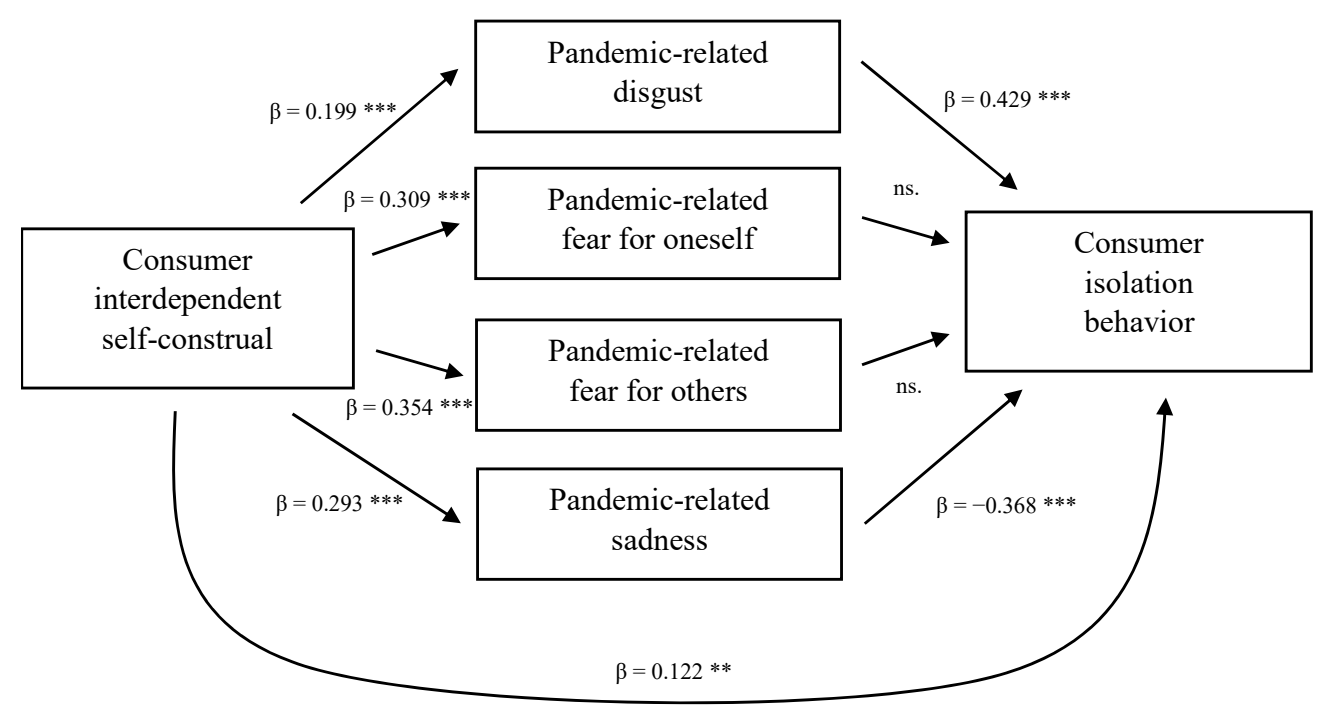

Figure 1. Mediation analysis of the relationship between consumer interdependent self-construal and pandemic-related isolation behavior through pandemic-related emotions (Study 1-October 2020). ${ }^{* *} p<0.001, * * p<0.01$.

\subsection{Discussion}

The findings suggest that interdependent self-construal is linked to pandemic-related disgust and consumer isolation behavior mainly through the attention-related mechanism. 
That is, in the pandemic context, interdependent self-construal may increase consumer preventive oriented focus on other people, leading to disgust and isolation behavior. Those effects appear to prevail over the opposite mechanism we proposed, which is based on higher identification with other people when self-construal is more interdependent.

In line with our proposition, the findings suggest that interdependent self-construal may increase pandemic-related sadness, which in turn may decrease isolation behavior. Consequently, the two opposite effects of interdependent self-construal on isolation behavior were evidenced: the positive one, through disgust, and the negative one, through sadness.

The role of pandemic-related fear appears to be less clear. While fear for oneself and fear for others are both positively related to interdependent self-construal, in line with our theorized mechanism based on preventive-oriented attention and sensitivity to other people, the effect of fear for oneself on isolation behavior is not visible. Perhaps it is because young adults, who were interviewed in the study, might be generally not scared of COVID-19, which was described as less dangerous to younger people.

Interestingly, the direct effect of interdependent self-construal on consumer isolation behavior is positive, suggesting the existence of other mediators apart from the four pandemic-related emotions we investigated. Perhaps other emotions (e.g., worry) or cognitions (e.g., risk perception) stemming from interdependent self-construal also contribute to consumer isolation behavior.

\section{Study 2 (January 2021)}

\subsection{Method}

\subsubsection{Procedure}

In January 2021, after the 2nd wave, when the number of cases was stabilized and the vaccination program was launched $[47,57]$, Polish university students recruited by students enrolled in marketing courses (826 participants, $50.8 \%$ females, $\mathrm{M}_{\text {age }}=22.3, \mathrm{SD}=2.7$ ) were asked to imagine buying electronic products, like in Study 1 . This time, we referred explicitly to the pandemic at the beginning of the questionnaire, to enhance the activation of pandemic-related thought. Namely, the instruction included the following sentence: 'Imagine that, because of the pandemic, you check the related information in the web right before you start looking for the products.' Like in Study 1, the participants first rated the degree of their isolation behavior during the purchase. Then, they were asked whether they had thought of the pandemic while answering the previous questions, related to isolation behavior (91\% confirmed they had). Next, the participants rated their pandemicrelated emotions the same way as in Study 1. Finally, the degree of horizontal and vertical interdependent self-construal was measured separately, followed by demographics.

\subsubsection{Measurements}

Consumer isolation behavior. To enhance the discriminant validity versus pandemicrelated disgust, we measured consumer isolation behavior, focusing on consumer preference to avoid offline shopping, that is, we excluded the aspect of physical contact with other people while shopping. We used the two relevant items from Study 1 ('If the price in an offline store was the same as in an online store, I would prefer to buy online.' , 'Preferably, I would complete the purchase staying home.', $r=0.826)$. We used five-point response scales (from 1 (strongly disagree) to 7 (strongly agree)), and the items were averaged into a single index. Like in Study 1, the item statements did not refer to the pandemic context to reduce possible demand biases.

Pandemic-related emotions. To measure the pandemic-related emotions, we used exactly the same measurement scales as in Study 1, and five-point response scales (from 1 (strongly disagree) to 7 (strongly agree) $)$, and obtained satisfactory reliability $\left(\alpha_{\text {sadness }}=0.933\right.$, $\left.\alpha_{\text {disgust }}=0.921, \alpha_{\text {fear for oneself }}=0.941, \alpha_{\text {fear for other people }}=0.938\right)$. Those items loaded on rotated EFA components in line with the measurement scales (principal components, $\mathrm{KMO}=0.902$, Bartlett's $p=0.000$, four components with the highest eigenvalues, the first component accounting for $27.1 \%$ of the variance, VARIMAX rotation, loadings above 0.500 ). 
Additionally, isolation behavior and disgust items loaded on rotated EFA components in line with the scales $(\mathrm{KMO}=0.835$, Bartlett's $p=0.000$, two components with eigenvalues above 1 , the first component accounting for $52.9 \%$ of the variance, VARIMAX rotation, loadings above 0.500). Like in Study 1, for each emotion, the corresponding items were averaged into a single index.

Vertical and horizontal dimensions of interdependent self-construal. To measure vertical and horizontal dimensions of interdependent self-construal, we used 16 items adapted from Sivadas et al. [45] (eight items per dimension), and five-point response scales (from 1 (strongly disagree) to 7 (strongly agree)). We excluded the item 'Children should be taught to place duty before pleasure.' (vertical subscale) as having a poor correlation with the other items and lowering Cronbach's alpha. Then we ran EFA on the remaining items $(\mathrm{KMO}=0.838$, Bartlett's $p=0.000$, two components with the highest eigenvalues, the first component accounting for $22.4 \%$ of the variance) and the items loaded in line with the subscales (VARIMAX rotation, loadings above 0.500), apart from three items (i.e., 'Children should feel honored if their parents receive a distinguished award.' (vertical subscale); 'If a relative were in financial difficulty, I would help within my means.', and 'My happiness depends very much on the happiness of those around me.' (horizontal subscale)). Consequently, we excluded those items, and obtained six items per dimension $\left(\alpha_{\text {vertical }}=0.761, \alpha_{\text {horizontal }}=0.707\right)$. For each dimension, the corresponding items were averaged into a single index. Additionally, all the 12 items were averaged into an overall index of interdependent self-construal.

\subsection{Results}

\subsubsection{The Role of Consumer Interdependent Self-Construal}

In a parallel mediation model (PROCESS, Hayes model 4) with pandemic-related emotions as mediators, consumer interdependent self-construal as an independent variable, and consumer isolation behavior (in terms of avoiding offline shopping) as a dependent variable (Figure $2 ; p_{\text {total }}>0.8 ; p_{\text {direct }}>0.9$, VIFs $<2.4$ ), a positive effect of pandemic-related disgust on isolation behavior occurred $(\beta=0.111, \mathrm{t}=2.536, p=0.011)$, thus supporting H1. Interdependent self-construal has a positive effect on disgust $(\beta=0.079, \mathrm{t}=2.266, p=0.024)$, thus supporting $\mathrm{H} 4 \mathrm{a}$ (based on the attention-related mechanism) over the competing H5a (based on the identity-related mechanism), but no indirect effect of interdependent selfconstrual on isolation behavior through disgust was observed $(p>0.05)$, providing support neither for $\mathrm{H} 4 \mathrm{~b}$ nor for $\mathrm{H} 5 \mathrm{~b}$. Pandemic-related fear for oneself has a positive effect on isolation behavior $(\beta=0.155, \mathrm{t}=3.230, p=0.001)$, thus providing support for $\mathrm{H} 2 \mathrm{a}$. The effect of interdependent self-construal on fear for oneself was positive $(\beta=0.196, t=5.730$, $p<0.0001)$, as was the indirect effect of interdependent self-construal on isolation behavior through fear for oneself $(\beta=0.030, \mathrm{CI} 95 \%(0.010,0.053))$, both supporting H8. The effect of pandemic-related fear for others on isolation behavior was positive $(\beta=0.148, t=3.554$, $p<0.0001)$, providing support for $\mathrm{H} 2 \mathrm{~b}$. The effect of interdependent self-construal on fear for others was positive $(\beta=0.274, \mathrm{t}=8.172, p<0.0001)$, as was the indirect effect of interdependent self-construal on isolation behavior through fear for others $(\beta=0.040$, CI95\%(0.016, 0.067)), both supporting H9. Finally, a negative effect of pandemic-related sadness on isolation behavior occurred $(\beta=-0.330, t=10.131, p<0.0001)$, thus supporting H3. The effect of interdependent self-construal on sadness was positive $(\beta=0.261, t=7.771$, $p<0.0001)$, and the indirect effect on isolation behavior through sadness was negative $(\beta=-0.086, \mathrm{CI} 95 \%(-0.115,-0.061))$, both providing support for H10. 


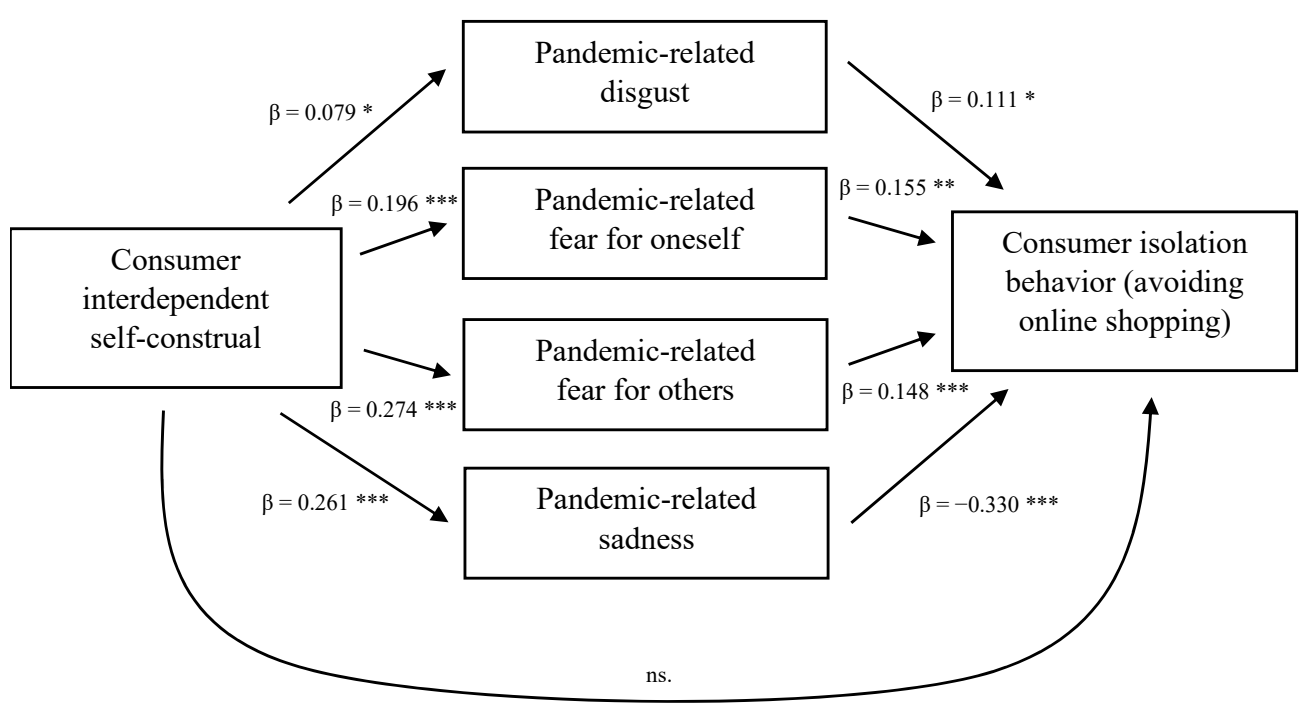

Figure 2. Mediation analysis of the relationship between consumer interdependent self-construal and pandemic-related isolation behavior through pandemic-related emotions (Study 2-January 2021). ${ }^{* * *} p<0.001,{ }^{* *} p<0.01,{ }^{*} p<0.05$.

\subsubsection{The Role of Consumer Vertical Collectivism}

In a parallel mediation model (PROCESS, Hayes model 4) with pandemic-related emotions as mediators, the vertical dimension of consumer interdependent self-construal as an independent variable, and consumer isolation behavior (in terms of avoiding offline shopping) as a dependent variable (Figure $3 ; p_{\text {total }}>0.6 ; p_{\text {direct }}>0.4$, VIFs $<2.4$ ), the vertical dimension of interdependent self-construal has a positive effect on disgust $(\beta=0.197$, $\mathrm{t}=5.760, p<0.0001)$, as well as a positive indirect effect on isolation behavior through disgust $(\beta=0.022$, CI95\%(0.005, 0.042)), thus supporting H6 (based on the attentionrelated mechanism).

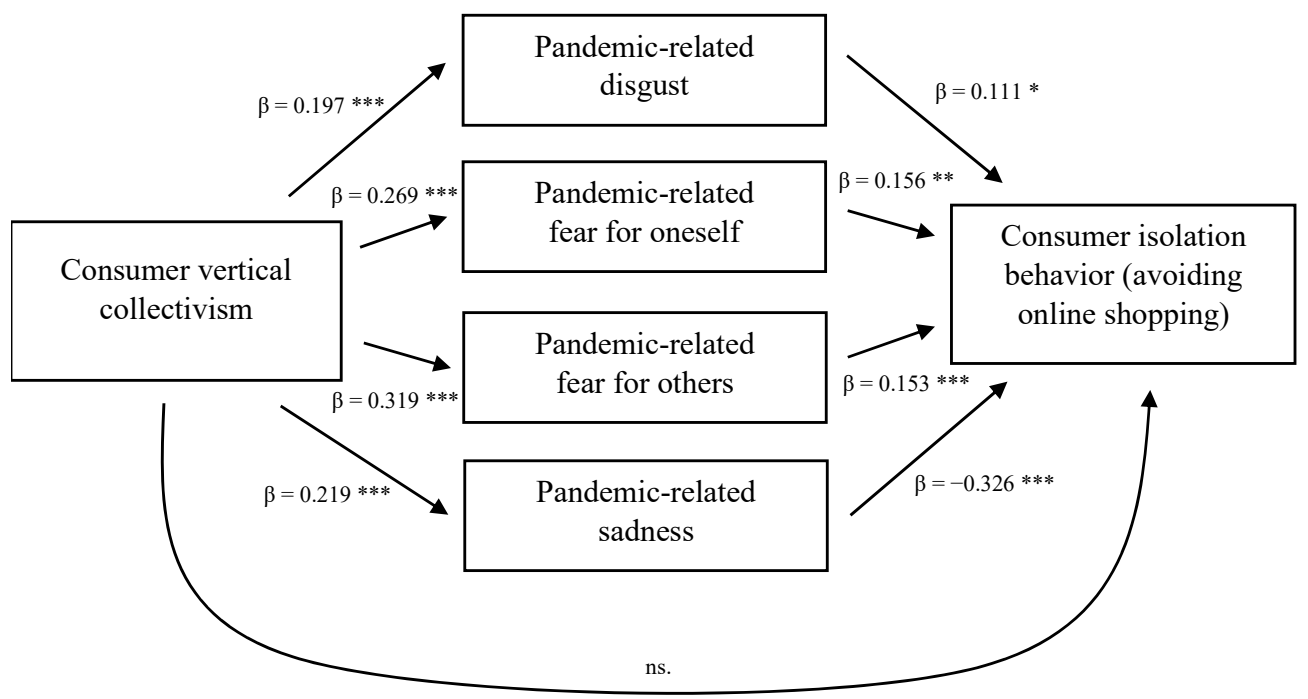

Figure 3. Mediation analysis of the relationship between consumer vertical collectivism and pandemic-related isolation behavior through pandemic-related emotions (Study 2-January 2021). ${ }^{* * *} p<0.001,{ }^{* *} p<0.01, * p<0.05$. 


\subsubsection{The Role of Consumer Horizontal Collectivism}

In a parallel mediation model (PROCESS, Hayes model 4) with pandemic-related emotions as mediators, the horizontal dimension of consumer interdependent self-construal as an independent variable, and consumer isolation behavior (in terms of avoiding offline shopping) as a dependent variable (Figure $4 ; p_{\text {total }}>0.3$; $p_{\text {direct }}=0.4$, VIFs $<2.4$ ), the horizontal dimension of interdependent self-construal has a negative effect on disgust ( $\beta=-0.093, t=2.677, p=0.008)$, as well as a negative indirect effect on isolation behavior through disgust $(\beta=-0.011, \mathrm{CI} 95 \%(-0.025,-0.001)$ ), thus supporting H7 (based on the identity-related mechanism).

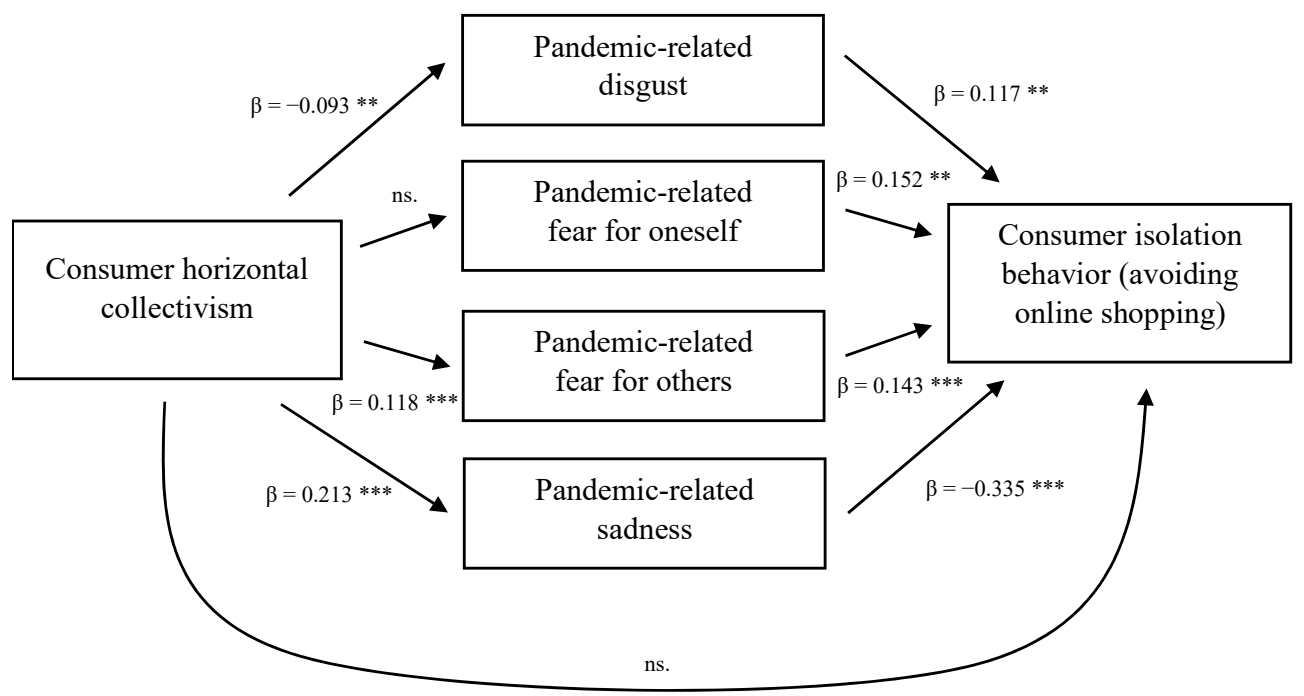

Figure 4. Mediation analysis of the relationship between consumer horizontal collectivism and pandemic related isolation behavior through pandemic-related emotions (Study 2-January 2021). *** $p<0.001, * * p<0.01$.

\subsection{Discussion}

The findings of Study 2 (January 2021) replicated the evidence collected in the previous study (October 2020) in support of the two opposite mechanisms of interdependent selfconstrual effect on isolation behavior: the positive influence through pandemic-related disgust (possibly related to higher preventive-oriented attention to other people), and the negative influence through pandemic-related sadness. As the two studies were conducted in different stages of the pandemic (i.e., Study 1 in a surge of new cases, and Study 2 in a period of stabilization in terms of new cases, and launching the vaccination program), together they indicate the robustness of the above effects.

In line with our propositions, the findings suggest the two dimensions of interdependent self-construal (i.e., vertical and horizontal) may induce different mechanisms of the effect of interdependent self-construal on isolation behavior through disgust. Namely, while the vertical dimension may increase disgust, and in turn isolation behavior, according to the attention-related mechanism, the horizontal dimension may reduce disgust, and in turn isolation behavior, according to the identity-related mechanism.

Compared to Study 1, the role of pandemic-related fear was more pronounced in Study 2. Apart from replicating the positive effect of interdependent self-construal on fear for oneself and fear for others, the findings of Study 2 indicate a positive effect of those two emotions on consumer isolation behavior. As the participants in Study 2 were even younger (thus potentially less scared of COVID-19) than those in Study 1, perhaps the role of the fear increased because pandemic-related fear was generally more developed in the later stages of the pandemic. 
Interestingly, the role of fear for oneself was larger in the case of the vertical dimension of self-construal as a factor (effect on fear for oneself: $\beta=0.269, \mathrm{t}=8.006, p<0.0001$; indirect effect on isolation behavior: $\beta=0.042, \mathrm{CI} 95 \%(0.016,0.072))$ than in the case of the horizontal dimension of self-construal as a factor (no significant effects). Perhaps feeling equal to other people, related to horizontal collectivism, reduces the fear of being infected by them.

It is noteworthy that interdependent self-construal had no significant direct effect on isolation behavior in Study 2, suggesting that the relationship between those constructs is fully (albeit inconsistently) mediated by the four emotions we investigate. As this was not the case in Study 1, this may indicate that the mechanisms determining consumer isolation behavior may substantially change in the course of the pandemic.

\section{Theoretical Implications}

To our best knowledge, this paper is the first attempt to link interdependent selfconstrual, pandemic-related emotions, and consumer pandemic-related isolation behavior. In this regard, we evidenced a few mechanisms stemming from interdependent selfconstrual. First, our results suggest that pandemic-related disgust (i.e., a tendency to avoid other people in the context of the pandemic), and consequently the isolation behavior, may be increased by interdependent self-construal, which supports the notions that interdependent self-construal is related to higher attention to other people [42] and a stronger orientation to avoiding negative outcomes [41]. However, our findings indicate that, of the two dimensions of interdependent self-construal (vertical vs. horizontal), the former may act according to the above attention-related mechanism, while the latter may act oppositely, as related to considering other people to be more identifiable with the self [41], and this may reduce disgust [34]. This way our research supports the above distinction within interdependent self-construal. Moreover, we evidence another mechanism, based on increased pandemic-related sadness (i.e., a negative feeling of limitations in contacting other people), which highlights the sociocentric aspect of interdependent self-construal [41], and consequently the need for social contacts resulting from sadness [38]. Our research also evidences the possible consequences of interdependent self-construal in terms of a higher fear for oneself and for others (i.e., that they may be infected), and therefore, a higher degree of isolation behavior. Those mechanisms, as well, reflect the preventive-oriented attention to other people, and sociocentrism (related to interdependent self-construal), and support the notion that isolation behavior during the pandemic may result from arousal-related emotions [25].

\section{Practical Implications}

Our results may guide both marketers and policymakers in accomplishing economic and sustainability goals related to consumer isolation behavior. For marketers, our results suggest that through activating interdependent self-construal, referring to the social context of the pandemic situation in marketing communication may trigger different behaviors in terms of consumer isolation, in the form of staying at home (vs. going outdoors) while shopping or avoiding contact with salespeople and other shoppers while shopping offline. If a marketer aims to encourage consumers to visit offline salespoints, then that social reference may be effective when it induces sadness related to the pandemic restrictions in contacting other people, or when it highlights the equality and similarity between people (activating more horizontal collectivism). On the other hand, if a marketer aims to increase online sales, the social reference may be effective when it induces disgust to other people as a potential source of infection, also by highlighting differences between people (activating more vertical collectivism), and the possibility of becoming infected oneself or infecting other people. Our results may be also applied in a cross-cultural context, by providing possible emotion-based mechanisms through which people may shop in more or less isolation in various cultures, differing in the level of collectivism, also in its vertical and horizontal aspect. Likewise, our results may help policymakers to discourage or encourage 
consumers to shop online (e.g., depending on the current pandemic situation) by referring in the communication to the social context of the pandemic, and the related emotions.

\section{Further Research Directions}

The mechanisms evidenced in this paper should be further investigated in various age groups (our studies focused on young adults) and cultures (our work is based on the Polish population, which shows moderate levels of collectivism). Another viewpoint may be the stage of the pandemic. Our studies were conducted in the first year of the COVID-19 pandemic. Along with further development of the pandemic situation, or in the case of new epidemics that may occur in the future, consumer reactions may change [20]. For example, the level of emotions may decrease when a pandemic becomes normality, and increase when developments are dynamic (e.g., a surge of new cases, reinforcing lockdown restrictions).

Next, it is worth studying the difference between vertical and horizontal collectivism in triggering pandemic-related fear for oneself. Our results suggest that the first dimension of interdependent self-construal is more related to this type of fear. However, that finding calls for theoretical explanation and more robust empirical support.

From the methodological point of view, the effect of interdependent self-construal on consumer isolation behavior should be further studied also by experimental manipulation of self-construal, emotions, and the degree of pandemic thought.

Finally, relevant research may link the relationships between pandemic situation, self-construal, emotions, and consumer isolation behavior with other sustainability-related constructs, as economic welfare, psychological well-being, and health. For example, a shift to online shopping among vertically oriented consumers may be beneficial from an environmental perspective and may help to contain the outbreak, but it may hamper social connections. On the other hand, a tendency of horizontally oriented consumers to shop offline and physically interact with other people may improve social connections, but worsen the epidemic control. Put together, our findings may contribute to investigating the more general problem, i.e., to what degree pandemic or epidemic events may trigger more sustainable consumer behavior [58-60].

Author Contributions: Conceptualization, W.T., R.B. and B.M.; methodology, W.T. and B.M.; data analysis, W.T.; writing—original draft, W.T.; writing—review and editing, W.T., R.B. and B.M.; project administration, W.T., R.B. and B.M.; funding acquisition, R.B. All authors have read and agreed to the published version of the manuscript.

Funding: This research was funded by SGH Warsaw School of Economics, Collegium of Management and Finance, grant number KZiF/S20/1.3.

Informed Consent Statement: Informed consent was obtained from all subjects involved in the study.

Data Availability Statement: The data presented in this study are available on request from the corresponding author.

Conflicts of Interest: The authors declare no conflict of interest. The funders had no role in the design of the study; in the collection, analyses, or interpretation of data; in the writing of the manuscript, or in the decision to publish the results.

\section{References}

1. Cutler, D. New Rules for the Pandemic Era. Jama 2020, 324, 1023-1024. [CrossRef]

2. Shin, H.; Kang, J. Reducing perceived health risk to attract hotel customers in the COVID-19 pandemic era: Focused on technology innovation for social distancing and cleanliness. Int. J. Hospital. Manag. 2020, 91, 102664. [CrossRef] [PubMed]

3. Alexa, L.; Apetrei, A.; Sapena, J. The COVID-19 Lockdown Effect on the Intention to Purchase Sustainable Brands. Sustainability 2021, 13, 3241. [CrossRef]

4. Hesham, F.; Riadh, H.; Sihem, N.K. What Have We Learned about the Effects of the COVID-19 Pandemic on Consumer Behavior? Sustainability 2021, 13, 4304. [CrossRef]

5. Koch, J.; Frommeyer, B.; Schewe, G. Online Shopping Motives during the COVID-19 Pandemic-Lessons from the Crisis. Sustainability 2020, 12, 10247. [CrossRef] 
6. Schmitt, V.G.H.; Cequea, M.M.; Neyra, J.M.V.; Ferasso, M. Consumption behavior and residential food waste during the COVID-19 pandemic outbreak in Brazil. Sustainability 2021, 13, 3702. [CrossRef]

7. Bae, S.Y.; Chang, P.J. The effect of coronavirus disease-19 (COVID-19) risk perception on behavioural intention towards 'untact' tourism in South Korea during the first wave of the pandemic (March 2020). Curr. Issues Tour. 2021, 24, 1017-1035. [CrossRef]

8. Chebli, A.; Said, F.B. The impact of covid-19 on tourist consumption behaviour: A perspective article. J. Tour. Manag. Res. 2020, 7, 196-207. [CrossRef]

9. Götz, F.M.; Gvirtz, A.; Galinsky, A.D.; Jachimowicz, J.M. How personality and policy predict pandemic behavior: Understanding sheltering-in-place in 55 countries at the onset of COVID-19. Am. Psychol. 2021, 76, 39-49. [CrossRef]

10. Kim, S.; Kim, J.; Badu-Baiden, F.; Giroux, M.; Choi, Y. Preference for robot service or human service in hotels? Impacts of the COVID-19 pandemic. Int. J. Hospital. Manag. 2021, 93, 102795. [CrossRef]

11. Lu, R.; Sheng, Y. From fear to hate: How the COVID-19 pandemic sparks racial animus in the United States. SSRN 2020. preprint. Available online: https:/ / ssrn.com/abstract=3646880 (accessed on 3 June 2021). [CrossRef]

12. Pham, V.K.; Tang, M.H.; Nguyen, T.L. Risk perception toward online shopping in Vietnam during the COVID-19 outbreak. J. Crit. Rev. 2020, 7, 1257-1269.

13. Sheth, J. Impact of Covid-19 on consumer behavior: Will the old habits return or die? J. Bus. Res. 2020, 117, 280-283. [CrossRef]

14. Turnšek, M.; Brumen, B.; Rangus, M.; Gorenak, M.; Mekinc, J.; Štuhec, T.L. Perceived threat of COVID-19 and future travel avoidance: Results from an early convenient sample in Slovenia. Acad. Turist. Tour. Innov. J. 2020, 13, 3-19. [CrossRef]

15. Zwanka, R.J.; Buff, C. COVID-19 generation: A conceptual framework of the consumer behavioral shifts to be caused by the COVID-19 pandemic. J. Int. Consum. Market. 2021, 33, 58-67. [CrossRef]

16. Ayers, J.D.; Beltran, D.G.; Alcock, J.; Baciu, C.; Claessens, S.; Cronk, L.; Hudson, N.M.; Miller, G.; Tidball, K.; Winfrey, P.; et al. How is the COVID-19 pandemic affecting cooperation? PsyArXiv 2020. preprint. [CrossRef]

17. Palmer, S.; Panchal, S.; O'Riordan, S. Could the experience of the COVID-19 pandemic have any positive impact on wellbeing? Eur. J. Appl. Pos. Psychol. 2020, 4, 1-13.

18. Ahn, D.; Shin, D.-H. Is the social use of media for seeking connectedness or for avoiding social isolation? Mechanisms underlying media use and subjective well-being. Comput. Hum. Behav. 2013, 29, 2453-2462. [CrossRef]

19. Snyder, D.G.; Newman, K.P. Reducing consumer loneliness through brand communities. J. Consum. Market. 2019, 36, 337-347. [CrossRef]

20. Chuo, H.-Y. Restaurant diners' self-protective behavior in response to an epidemic crisis. Int. J. Hospital. Manag. 2014, 38, 74-83. [CrossRef]

21. Jung, H.; Park, M.; Hong, K.; Hyun, E. The impact of an epidemic outbreak on consumer expenditures: An empirical assessment for MERS Korea. Sustainability 2016, 8, 454. [CrossRef]

22. Cahyanto, I.; Wiblishauser, M.; Pennington-Gray, L.; Schroeder, A. The dynamics of travel avoidance: The case of Ebola in the U.S. Tour. Manag. Perspect. 2016, 20, 195-203. [CrossRef] [PubMed]

23. Escandon-Barbosa, D.; Hurtado, A.; Gomez, A. Factors Affecting Voluntary Self-Isolation Behavior to Cope with a Pandemic: Empirical Evidence from Colombia vs. Spain in Times of COVID-19. Behav. Sci. 2021, 11, 35. [CrossRef]

24. Laato, S.; Islam, A.N.; Farooq, A.; Dhir, A. Unusual purchasing behavior during the early stages of the COVID-19 pandemic: The stimulus-organism-response approach. J. Retail. Consum. Serv. 2020, 57, 102224. [CrossRef]

25. Szymkowiak, A.; Gaczek, P.; Jeganathan, K.; Kulawik, P. The impact of emotions on shopping behavior during epidemic. What a business can do to protect customers. J. Consum. Behav. 2021, 20, 48-60. [CrossRef]

26. Bundorf, M.K.; DeMatteis, J.; Miller, G.; Polyakova, M.; Streeter, J.L.; Wivagg, J. Risk Perceptions and Protective Behaviors: Evidence from COVID-19 Pandemic (No. w28741). Nat. Bureau Econom. Res. 2020, 28741, 1-40.

27. Abdullah, M.; Nazam, A.; Hussain, S.A.; Aslam, A.B.; Javid, M.A. Measuring changes in travel behavior pattern due to COVID-19 in a developing country: A case study of Pakistan. Trans. Policy 2021, 108, 21-33. [CrossRef]

28. Wang, X.; Wong, Y.D.; Yuen, K.F. Rise of 'Lonely' Consumers in the post-COVID-19 era: A synthesised review on psychological, commercial and social implications. Int. J. Environ. Res. Publ. Health 2021, 18, 404. [CrossRef]

29. Akhtar, N.; Akhtar, M.N.; Usman, M.; Ali, M.; Iqbal Siddiqi, U. COVID-19 restrictions and consumers' psychological reactance toward offline shopping freedom restoration. Serv. Ind. J. 2020, 40, 891-913. [CrossRef]

30. Aslam, F.; Awan, T.M.; Syed, J.H.; Kashif, A.; Parveen, M. Sentiments and emotions evoked by news headlines of coronavirus disease (COVID-19) outbreak. Hum. Soc. Sci. Commun. 2020, 7, 1-9. [CrossRef]

31. Chehal, D.; Gupta, P.; Gulati, P. COVID-19 pandemic lockdown: An emotional health perspective of Indians on Twitter. Int. J. Soc. Psychiat. 2020. online ahead of print. Available online: https://journals.sagepub.com/doi/full/10.1177/0020764020940741 (accessed on 3 June 2021). [CrossRef]

32. Liu, P.L. COVID-19 information seeking on digital media and preventive behaviors: The mediation role of worry. Cyberpsychology. Behav. Soc. Netw. 2020, 23, 677-682. [CrossRef] [PubMed]

33. Odekerken-Schröder, G.; Mele, C.; Russo-Spena, T.; Mahr, D.; Ruggiero, A. Mitigating loneliness with companion robots in the COVID-19 pandemic and beyond: An integrative framework and research agenda. J. Serv. Manag. 2020, 31, 1149-1162. [CrossRef]

34. Morales, A.; Wu, E. Disgust and identity. In Identity and Consumption; Ruvio, A., Belk, R., Eds.; Routledge: London, UK; New York, NY, USA, 2012; pp. 72-79. 
35. Söderlund, M. Employee norm-violations in the service encounter during the corona pandemic and their impact on customer satisfaction. J. Retail. Consum. Serv. 2020, 57, 102209. [CrossRef]

36. Oaten, M.; Stevenson, R.J.; Case, T.I. Disgust as a disease-avoidance mechanism. Psychol. Bullet. 2009, 135, 303-321. [CrossRef] [PubMed]

37. Yin, J.; Ni, Y. COVID-19 event strength, psychological safety, and avoidance coping behaviors for employees in the tourism industry. J. Hospital. Tour. Manag. 2021, 47, 431-442. [CrossRef]

38. Gray, H.M.; Ishii, K.; Ambady, N. Misery loves company: When sadness increases the desire for social connectedness. Personal. Soc. Psychol. Bullet. 2011, 37, 1438-1448. [CrossRef]

39. Garg, N.; Lerner, J.S. Sadness and consumption. J. Consum. Psychol. 2013, 23, 106-113. [CrossRef]

40. Lei, S.; Wang, X.; Peng, L.; Guo, Y. "I" seek differentiation and "we" seek assimilation: The impact of self-expressive customization on consumers' willingness to pay a premium. J. Prod. Brand Manag. 2020, ahead-of-print. [CrossRef]

41. Shavitt, S.; Lee, A.Y.; Johnson, T.P. Cross-cultural consumer psychology. In Handbook of Consumer Psychology; Haugtvedt, C., Herr, P., Kardes, F., Eds.; Mahwah: Erlbaum, NJ, USA, 2008; pp. 1103-1131.

42. Owe, E.; Vignoles, V.L.; Becker, M.; Brown, R.; Smith, P.B.; Lee, S.W.; Jalal, B. Contextualism as an important facet of individualismcollectivism: Personhood beliefs across 37 national groups. J. Cross Cul. Psychol. 2013, 44, 24-45. [CrossRef]

43. Hess, U.; Blaison, C.; Kafetsios, K. Judging facial emotion expressions in context: The influence of culture and self-construal orientation. J. Nonv. Behav. 2016, 40, 55-64. [CrossRef]

44. Lee, A.Y.; Aaker, J.L.; Gardner, W.L. The pleasures and pains of distinct self-construals: The role of interdependence in regulatory focus. J. Personal. Soc. Psychol. 2000, 78, 1122-1134. [CrossRef]

45. Sivadas, E.; Bruvold, N.T.; Nelson, M.R. A reduced version of the horizontal and vertical individualism and collectivism scale: A four-country assessment. J. Bus. Res. 2008, 61, 201-210. [CrossRef]

46. Singelis, T.M.; Triandis, H.C.; Bhawuk, D.P.S.; Gelfand, B.J. Horizontal and vertical dimensions of individualism and collectivism: A theoretical and measurement refinement. Cross Cultur. Res. 1995, 29, 240-275. [CrossRef]

47. GCDL, Global Change Data Lab. Statistics and research. Coronavirus Pandemic (COVID-19). Available online: https:// ourworldindata.org/coronavirus (accessed on 1 June 2021).

48. Feldman, J.M.; Lynch, J.G., Jr. Self-generated validity and other effects of measurement on belief, attitude, intention, and behavior. J. Appl. Psychol. 1988, 73, 421-435. [CrossRef]

49. Lunardo, R.; Rickard, B. How do consumers respond to fun wine labels? Br. Food J. 2020, 122, 2603-2619. [CrossRef]

50. Shimp, T.A.; Stuart, E.W. The role of disgust as an emotional mediator of advertising effects. J. Adv. 2004, 33, 43-53. [CrossRef]

51. Duhachek, A. Coping: A multidimensional, hierarchical framework of responses to stressful consumption episodes. J. Consum. Res. 2005, 32, 41-53. [CrossRef]

52. Williams, P.; Aaker, J.L. Can mixed emotions peacefully coexist? J. Consum. Res. 2002, 28, 636-649. [CrossRef]

53. Fuller, C.M.; Simmering, M.J.; Atinc, G.; Atinc, Y.; Babin, B.J. Common methods variance detection in business research. J. Bus. Res. 2016, 69, 3192-3198. [CrossRef]

54. McCole, P.; Ramsey, E.; Williams, J. Trust considerations on attitudes towards online purchasing: The moderating effect of privacy and security concerns. J. Bus. Res. 2010, 63, 1018-1024. [CrossRef]

55. Pilarska, A. Polska adaptacja Skali Konstruktów Ja. Stud. Psychol. 2011, 49, 21-34.

56. Singelis, T.M. The measurement of independent and interdependent self-construals. Person. Soc. Psychol. Bullet. 1994, 20, 580-591. [CrossRef]

57. Reuters. Coronavirus Pandemic Back on Upward Trend in Poland-Minister. Available online: https://www.reuters.com/article/ health-coronavirus-poland-idUSL8N2KM2LC (accessed on 1 June 2021).

58. Marinković, V.; Lazarević, J. Eating habits and consumer food shopping behaviour during COVID-19 virus pandemic: Insights from Serbia. Br. Food J. 2021, ahead-of-print. [CrossRef]

59. Orîndaru, A.; Popescu, M.-F.; Căescu, Ș.-C.; Botezatu, F.; Florescu, M.S.; Runceanu-Albu, C.-C. Leveraging COVID-19 Outbreak for Shaping a More Sustainable Consumer Behavior. Sustainability 2021, 13, 5762. [CrossRef]

60. Severo, E.A.; De Guimarães, J.C.F.; Dellarmelin, M.L. Impact of the COVID-19 pandemic on environmental awareness, sustainable consumption and social responsibility: Evidence from generations in Brazil and Portugal. J. Clean. Prod. 2021, $286,124947$. [CrossRef] [PubMed] 